\title{
Timing and outcomes after silicone oil removal in proliferative vitreoretinopathy: a retrospective clinical series
}

\author{
Renata Leite De Pinho Tavares ${ }^{1 *}$, Mário Junqueira Nóbrega², Fernando Amaral Junqueira Nóbrega ${ }^{3}$, \\ Fernando José De Novelli ${ }^{2}$ and Carlos Augusto Cardim De Oliveira ${ }^{1}$
}

\begin{abstract}
Objective: To evaluate anatomical and functional outcomes after silicone oil extraction in patients with retinal detachment and proliferative vitreoretinopathy in an eye care referral center in Joinville, SC, southern Brazil.

Methods: Retrospective, noncomparative study of patients with retinal detachment and posterior proliferative vitreoretinopathy followed up after silicone oil removal. Prophylactic 360-degree peripheral laser photocoagulation was performed one to three months before silicone oil extraction. Patients with cataract underwent a combined clear corneal phacoemulsification with intraocular lens implantation in the same procedure. Anatomical outcomes were related to the duration of silicone oil tamponade and the surgical procedure performed. Functional outcomes were divided into three categories (stability, worsening, or improvement) according to visual acuity variation before the surgery and at the last follow-up visit.

Results: Fifty-three patients were followed up for a mean period of 1,262 days. Fourteen eyes (26.4\%) underwent cataract surgery combined with silicone oil extraction. Forty-eight eyes (90.5\%) had attached retina at the last follow-up examination. Time of intraocular tamponade and association of phacoemulsification with silicone oil extraction were not considered as risk factors for retinal redetachment. Twenty-three cases (43.4\%) showed visual acuity improvement, whereas 11 cases (20.8\%) were stable and 19 cases (35.8\%) showed visual acuity worsening. Five patients with attached retina had unexplained optic disc atrophy.

Conclusion: Most patients had good anatomical and visual outcomes after silicone oil extraction. Prophylactic 360-degree laser retinopexy may have led to favorable outcomes. Benefits of silicone oil extraction and the associated risks of complications due to a new surgical procedure must be carefully evaluated before surgical indication.
\end{abstract}

Keywords: Retinal detachment, Silicone oil, Proliferative vitreoretinopathy

\section{Background}

Proliferative vitreoretinopathy (PVR) is an important complication of rhegmatogenous retinal detachment and its treatment requires a long-acting endotamponade, such as silicone oil, to reduce the rate of recurrent retinal detachment [1,2].

To avoid long-term complications due to the presence of silicone oil inside the eye, such as cataract, glaucoma and ceratopathy, its removal is usually necessary. Nevertheless,

\footnotetext{
*Correspondence: re_tavares@hotmail.com

'Hospital de Olhos de Londrina (HOFTALON), Londrina, PR - Brazil, Rua Belo Horizonte 1330, ap 1401, Londrina, PR CEP 86020-060, Brazil

Full list of author information is available at the end of the article
}

after silicone oil extraction, recurrence of PVR and consequently retinal redetachment can occur. It is generally associated with residual vitreoretinal traction at the vitreous base [3,4]; some other factors may also contribute to unfavorable outcomes, like intra and postoperative inflammation, intraoperative bleeding, retinal pigment epithelium exposure, retinectomy and extended duration of the surgical procedure.

As suggested by some authors, a prophylactic 360degree laser retinopexy prior to silicone oil extraction may help to reduce retinal redetachment rates [5-7]. Additionally, in spite of a permanent attached retina,

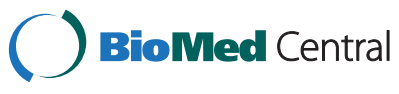

(C) 2015 Tavares et al.; licensee BioMed Central. This is an Open Access article distributed under the terms of the Creative Commons Attribution License (http://creativecommons.org/licenses/by/4.0), which permits unrestricted use, distribution, and reproduction in any medium, provided the original work is properly credited. The Creative Commons Public Domain Dedication waiver (http://creativecommons.org/publicdomain/zero/1.0/) applies to the data made available in this article, unless otherwise stated. 
some patients may have unexplained vision loss after silicone oil extraction [1,3-7].

The objective of the present study is to evaluate anatomical and functional outcomes after silicone oil removal in patients with retinal detachment and proliferative vitreoretinopathy in an eye care referral center in Joinville, SC, southern Brazil.

\section{Methods}

A retrospective, noncomparative clinical series of patients with rhegmatogenous retinal detachment and posterior PVR grade A, B, C1, C2, C3, D1 and D2 examined after silicone oil extraction. Surgical interventions were performed between January 1997 and February 2013. The patients were examined and operated on by the same surgeon (MJN).

The initial operative procedure consisted of 20-gauge pars plana vitrectomy, 360-degree scleral buckle, laser endophotocoagulation surrounding retinal tears, and infusion of 5000-centistoke silicone oil (Ophthalmos ${ }^{\circ}$, São Paulo, SP) into the vitreous cavity (Figure 1). Prophylactic 360-degree peripheral laser photocoagulation was performed one to three months before silicone oil extraction. Laser spots were delivered to the scleral buckle area in two or three rows via slit lamp.

Silicone oil was extracted between 6 weeks and 12 months after the initial procedure through a standard two-port pars plana surgery. If there was cataract, a combined clear corneal incision phacoemulsification and intraocular lens (IOL) implantation was performed. During follow-up period, logMAR best-corrected visual acuity (BCVA), intraocular pressure (IOP), slit-lamp biomicroscopy, indirect and slit-lamp ophthalmoscopy were registered.

Functional outcomes were divided into three categories. Patients who had a final logMAR BCVA showing a 0.1-variation compared to the baseline BCVA were considered stabilized; a visual acuity variation was significant if the difference between baseline and final BCVA was $0.2 \log$ MAR. A severe visual worsening was registered if there was a BCVA reduction of $0.3 \log$ MAR or more.

Statistical analysis was performed using STATA version 12.0 (Texas USA). Categorical variables were expressed by frequencies and percentages and the continuous variables were expressed through means and standard deviation, with a confidence interval of 95\%. The Student's t-test was used to evaluate relation between mean period of silicone oil tamponade and retinal detachment as well as to compare visual acuity means before and after silicone oil removal. Pearson's Chi-square test, or the Fischer exact test, was used to assess causality of using the combined procedure (silicone oil removal, phacoemulsification and IOL implantation) with retinal re-detachment cases, and also correlate it with final visual acuity.

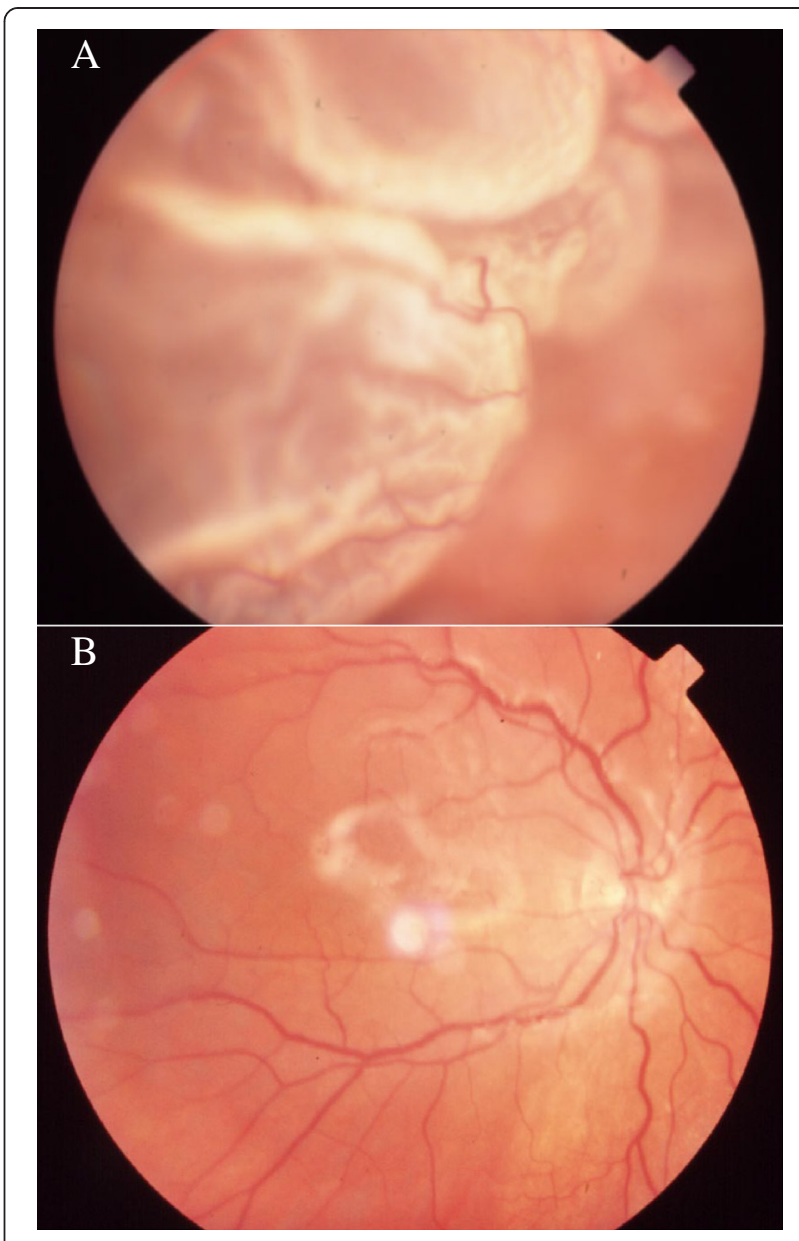

Figure 1 Inicial operative procedure: rhegmatogenous retinal detachment and grade $C$ posterior proliferative vitreoretinopathy (A) and postoperative result after silicone oil infusion (B).

Significance level of $5 \%$ was accepted to reject the null hypothesis.

The informed consent to participate in the study was obtained from each patient. Hospital Municipal São José's ethical committee, Joinville - Santa Catarina, Brazil, approved the research according to the project number: 240.558 .

\section{Results}

Fifty-three eyes of 53 patients were included; thirty-three (62\%) patients were male; mean age was 52.7 years (range 16-79 years). According to PVR classification, $3.8 \%(2 / 53)$ of the patients were grade A PVR; $5.6 \%$ (3/53) grade B PVR; 32.1\% (17/53) grade C1 PVR; $18.9 \%(10 / 53)$ grade C2 PVR; $5.6 \%$ (3/53) grade C3 PVR; $1.9 \%(1 / 53)$ grade D1 PVR and $1.9 \%(1 / 53)$ grade D2 PVR; $30.2 \%(16 / 53)$ of the patients had no classifying register. Follow-up varied from 256 days to 4,421 days (mean 1,262 + -944 days). The median time 
of silicone oil extraction was 196 days after its placement. The mean intraocular pressure was $15.6+-7.4$ before and $14.8+-6.2$ after silicone oil removal. Phacoemulsification with IOL implantation was combined with silicone oil removal in 14 eyes (26.4\%) (Figure 2A).

Forty-eight $(90.5 \%)$ patients had attached retina at the last follow-up visit (Figure $2 \mathrm{~B}$ ). The mean period of silicone oil duration in the vitreous cavity was $228+-152$ and $275+-265$ days in cases with and without redetachment, respectively. There was no association between duration of intraocular silicone oil and risk for retinal redetachment $(p=0.6997)$. The rate of retinal redetachment in patients submitted to phacoemulsification combined with silicone oil extraction was $21.4 \%$ (Figure 2C), which represented $60 \%$ of all the redetachment cases (Figure 2D), but not statiscally significant ( $\mathrm{p}=0.0735)$.

Twenty-three patients (43.4\%) showed BCVA improvement, eleven patients (20.8\%) were stabilized and 19 patients $(35.8 \%)$ had a BVCA worsening. Mean preoperative and postoperative values of BCVA were $0.95 \operatorname{logMAR}$ $($ Snellen $=20 / 160)$ and $1.01 \log$ MAR $($ Snellen $=20 / 200)$ respectively (Figure 3 ). Severe visual worsening was observed in 15 patients $(28.3 \%)$, of whom five had unexplained optic disc atrophy.

Combined phacoemulsification with intraocular lens implant and removal of silicone oil did not influence the final visual acuity when compared to the isolated extraction of silicone oil $(\mathrm{p}=0.426)$. In addition, BCVA worsening could not be directly associated with silicone oil removal $(\mathrm{p}=0.6598)$.

\section{Discussion}

Several factors may be related to anatomic and functional outcomes after silicone oil extraction in PVR cases. In this study, the relation between duration of silicone oil tamponade and incidence of retinal redetachment was not established. In the literature, while some authors did not consider the timing of silicone oil removal as a risk factor for anatomic success rate $[4,8,9]$, others observed that shorter tamponade duration had lower attachment rate than longer tamponade duration $[10,11]$.

The association of encircling buckle and peripheral laser photocoagulation prior to silicone oil extraction has been previously reported as safe and advantageous [9,12-15]. A 360-degrees laser performed previously to surgery may improve peripheral chorioretinal adhesion and avoid retinal redetachment in spite of residual vitreous base traction $[3,7,16]$.

Compared to other studies (Table 1), the present report showed a low redetachment rate $(9.5 \%)$ after silicone oil extraction. This may be due to improved surgical management of complicated retinal detachments in the last years, especially adequate vitreous removal with the use of widefield viewing systems $[7,12]$.

A combined surgery, with longer duration and more intense inflammation, may predispose to postoperative

\section{A Rhegmatogenous Retinal Detachment and Grade C Posterlor PVR}

Phacoemulsification combined with silicon oil removal

Single Silicone oil removal

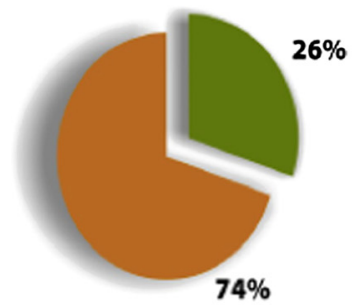

$\mathbf{C}_{\mathrm{P}}$

Patients Submitted to Phacoemulsification

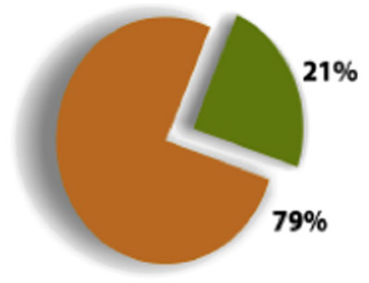

Redetachment

No redetachment
B Redetachment Rate

Redetachment

No redetachment

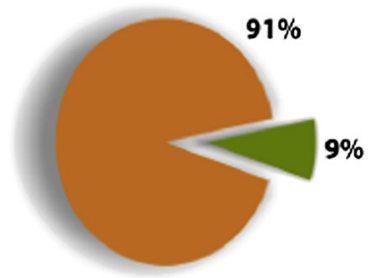

D Percentage of Phacoemulsification in

Retinal Redetachment Cases

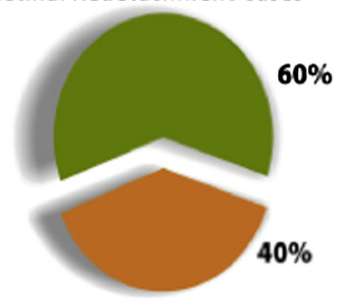

Phacoemulsification combined with silicon oil removal

Single Silicone oil removal

Figure 2 Anatomical results after silicone oil removal and comparison between single and combined procedure with phacoemulsification. 


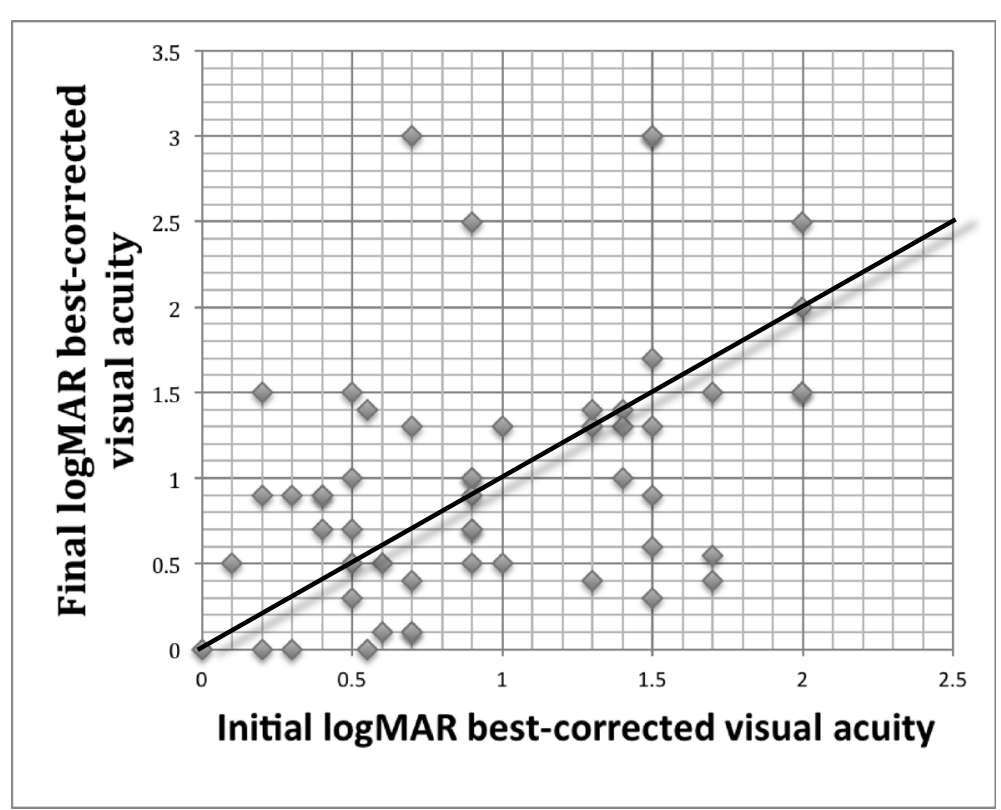

Figure 3 Comparison of BCVA between preoperative examination and last follow-up assessment.

PVR and retinal redetachment [2]. The present study showed a higher rate of retinal detachment recurrence in eyes submitted to silicone oil extraction associated with cataract surgery than eyes that had only silicone oil removal (21.4\% vs. 5.1\%); however, this result was not statistically significant $(\mathrm{p}=0.0735)$.

Functional outcomes were not fully correlated with anatomical outcomes. To date, there is no definite explanation for vision loss or optic atrophy after silicone oil extraction. A long-term and close contact of silicone oil with the retina may cause toxicity; abnormal potassium exchanges and dysfunction of central Müller cells

Table 1 Previous studies showing rate of retinal redetachment after silicone oil extraction and number of treated eyes

\begin{tabular}{lll}
\hline & \% Redetach & Treat eyes \\
\hline Bassat et al. [22] (2000) & 9.3 & 32 \\
Flaxel et al. [23] (2000) & 34 & 62 \\
Scholda et al. [11] (2000) & 16.1 & 112 \\
Assi et al. [24] (2001) & 20.2 & 74 \\
Falkner et al. [1] (2001) & 16.5 & 103 \\
Jonas et al. [4] (2001) & 27.6 & 185 \\
Jiang et al. [25] (2002) & 20.2 & 168 \\
Unlu et al. [26] (2004) & 9.5 & 21 \\
Scott et al. [27] (2005) & 21 & 57 \\
Soheilian et al. [28] (2006) & 28 & 82 \\
Lam et al. [8] (2008) & 18.4 & 147 \\
Jain et al. [15] (2010) & 11.6 & 300 \\
Nagpal et al. [9] (2012) & 12.7 & 370 \\
\hline
\end{tabular}

may also explain a shallow foveal depression and vision loss [13-15].

Besides surgical intervention, new types of treatment for PVR are being tested in clinical trials. Several studies have been performed, including use of many drugs, such as daunorubicin, corticosteroids, 5-fluorouracil, heparin and colchicine [17-21]. Nonetheless, PVR is still a challenge and continues to be the most common cause of surgical failure following retinal detachment surgery.

The main limitation of the present study is its retrospective and noncomparative design. Because of the patients' records were not standardized, some complementary data, such as analysis of macular optic coherence tomography and visual field, could not be included. The size of the sample may also have influenced the results; a higher number of treated eyes could permit other comparisons and demonstrate significant differences between the outcomes.

As described in other reports, this study shows how critical is the dilemma concerning treatment of complex rhegmatogenous retinal detachment. Silicone oil removal provided favorable anatomical and functional results in the majority of the operated eyes and prophylactic peripheral laser retinopexy may have contributed to this. However, some eyes developed unexplained vision loss after silicone oil extraction and there was also a trend to retinal redetachment when silicone oil removal was combined with phacoemulsification and intraocular lens placement.

\section{Conclusion}

In summary, low detachment rate may be due to improved surgical management of complicated retinal detachments 
and also to prophylactic 360- degree retinopexy. Surgeons must be aware of adverse results associated with silicone oil removal. Benefits of silicone oil extraction must be outweighed against its extended duration in the eye and the possibility of complications after a new surgical procedure.

\section{Abbreviations}

PVR: Proliferative vitreoretinopathy; IOL: Intraocular lens; BCVA: Best-corrected visual acuity.

\section{Competing interests}

The authors declare that they have no competing interests.

\section{Authors' contributions}

RLPT: conception and design, acquisition, analysis and interpretation of data; involved in drafting the manuscript and its revising. MJN: conception, design, contributed in drafting, responsible for critical revision and has given final approval of the version to be published. FAJN: design, acquisition and interpretation of data. FJN: conception, design and revising. CACO: statistical analysis and interpretation of data. All authors read and approved the final manuscript.

\section{Author details}

${ }^{1}$ Hospital de Olhos de Londrina (HOFTALON), Londrina, PR - Brazil, Rua Belo Horizonte 1330, ap 1401, Londrina, PR CEP 86020-060, Brazil. ${ }^{2}$ Hospital de Olhos Sadalla, Universidade da Região de Joinville, Amin Ghanem, Joinville, SC, Brazil. ${ }^{3}$ Universidade de Alfenas (UNIFENAS), Alfenas, MG, Brazil.

Received: 4 December 2014 Accepted: 12 February 2015

Published online: 15 April 2015

\section{References}

1. Falkner $\mathrm{Cl}$, Binder $\mathrm{S}$, Kruger A. Outcome after silicone oil removal. Br J Ophthalmol. 2001;85(11):1324-7.

2. Ryan SJ. The pathophysiology of proliferative vitreoretinopathy in its management. Am J Ophthalmol. 1985;100(1):188-93.

3. Jain $\mathrm{P}$, Napgal M, Videkar R, Napgal K, Patil A: Evaluation of possible risk factors for retinal re-detachment after silicone oil removal. In: AIOC, Retina/Nitreous session - IV. 2010:655-6.

4. Jonas JB, Knor HL, Rank RM, Budde WM. Retinal redetachment after removal of intraocular silicone oil tamponade. Br J Ophthalmol. 2001;85(10):1203-7.

5. Hutton LW, Azen PS, Blumenkranz SM, Lai MY, McCuen BW, Han DP, et al. The effects of silicone oil removal. Silicone study report 6 . Arch Ophthalmol. 1994;112(6):778-85.

6. Steel $\mathrm{DH}$, Weir $\mathrm{P}$, James $\mathrm{CR}$. Silicone assisted, argon laser confinement of recurrent proliferative vitreoretinopathy relates retinal detachment: a technique to allow silicone oil removal in problem eyes. Br J Ophthalmol. 1997:81(9):765-70.

7. Tufail A, Schwartz SD, Gregor ZJ: Prophylactic argon laser retinopexy prior to removal of silicone oil: a pilot study. Eye (Lond).1997;11 (Pt 3):328-30.

8. Lam RF, Cheung BTO, Yuen CYF, Wong D, Lam DSC, Lai WW. Retinal redetachment after silicone oil removal in proliferative vitreoretinopathy: a prognostic factor analysis. Am J Ophthalmol. 2008;145(3):527-33.

9. Nagpal MP, Videkar RP, Nagpal KM. Factors having implications on reretinal detachments after silicone oil removal. Indian J Ophthalmol. 2012;60(6):517-20.

10. Tan HS, Dell'omo R, Mura M. Silicone oil removal after rhegmatogenous retinal detachment: comparing techniques. Eye (Lond). 2012;26(3):444-7.

11. Scholda C, Egger S, Lakits A, Walch K, von Eckardstein E, Biowski R. Retinal detachment after silicone oil tamponade. Acta Ophtalmol Scand. 2000;78(2):182-6.

12. Laidlaw DA, Karina N, Bunce C, Aylward GW, Gregor ZJ. Is prophylactic 360-degree laser retinopexy protective? risk factors for retinal redetachment after removal of silicone oil. Ophthalmology. 2002;109(1):53-8.

13. Cazabon S, Groenewald C, Pearce IA, Wong D. Visual loss following removal of intraocular silicone oil. Br J Ophthalmol. 2005;89(7):799-802.

14. Williams PD, Fuller CG, Scott IU, Fuller DG, Flynn HW. Vision loss associates with the use and removal of intraocular silicone oil. Clin Ophthalmol. 2008;2(4):955-9.
15. Jain N, McCuen 2nd BW, Mruthyunjaya P. Unanticipated vision loss after pars plana vitrectomy. Surv Ophthalmol. 2012;57(2):91-104.

16. Avitabile T, Longo A, Lentini G, Reibaldi A. Retinal detachment after silicone oil removal is prevented by 360 degrees laser treatment. $\mathrm{Br} J$ Ophthalmol. 2008;92:1479-82.

17. Sun JK, Arroyo JG. Adjunctive therapies for proliferative vitreoretinopathy. Int Ophthalmol Clin. 2004;44(3):1-10.

18. Wiedemann P, Hilgers RD, Bauer P, Heimann K, Daunomycin Study Group. Adjunctive daunorubicin in the treatment of proliferative vitreoretinopathy: results of a multicenter clinical trial. Am J Ophthalmol. 1998;126(4):550-9.

19. Shinohara K, Tanaka M, Sakuma T, Kobayashi Y. Efficacy of daunorubicin encapsulated in liposome for the treatment of proliferative vitreoretinopathy. Ophthalmic Surg Lasers Imaging. 2003;34(4):299-305.

20. Asaria RH, Kon CH, Bunce C, Charteris DG, Wong D, Khaw PT, et al. Adjuvant 5-fluorouracil and heparin prevents proliferative vitreoretinopathy: results from a randomized, double-blind, controlled clinical trial. Ophthalmology. 2001;108(7):1179-83.

21. Wickham L, Bunce C, Wong D, McGurn D, Charteris DG. Randomized controlled trial of combined 5-Fluorouracil and low-molecular-weight heparin in the management of unselected rhegmatogenous retinal detachments undergoing primary vitrectomy. Ophthalmology. 2007;114(4):698-704

22. Bassat IB, Desatnik H, Alhalel A, Treister G, Moisseiev J. Reduced rate of retinal detachment following silicone oil removal. Retina. 2000;20(6):597-603.

23. Flaxel CJ, Mitchell SM, Aylward GW. Visual outcome after silicone oil removal and recurrent retinal detachment repair. Eye. 2000;14:834-8.

24. Assi A, Woodruff S, Gotzaridis E, Bunce C, Sullivan P. Combined phacoemulsification and transpupillary drainage of silicone oil: results and complications. Br J Ophthalmol. 2001;85(8):942-5.

25. Jiang F, Krause M, Ruprecht KW, Hille K: Management and results of retinal detachment after silicone oil removal. Ophthalmologica. 2002 Sep-Oct;216(5):341-5.

26. Unlu N, Kocaoglan H, Acar MA, Sargin M, Aslan BS, Duman S. Outcome of complex retinal detachment surgery after silicone oil removal. Int Ophthalmol. 2004;25(1):33-6.

27. 27. Scott IU, Flynn Jr HW, Murray TG, Smiddy WE, Davis JL, Feuer WJ: Outcomes of complex retinal detachment repair using 1000-vs 5000- centistoke silicone oil. Arch Ophthalmol. 2005 Apr;123(4):473-8.

28. Soheilian M, Mazareei M, Mohammadpour M, Rahmani B: Comparison of silicon oil removal with various viscosities after complex retinal detachment surgery. BMC Ophthalmol. 2006 May; 31;6:21.

\section{Submit your next manuscript to BioMed Central and take full advantage of:}

- Convenient online submission

- Thorough peer review

- No space constraints or color figure charges

- Immediate publication on acceptance

- Inclusion in PubMed, CAS, Scopus and Google Scholar

- Research which is freely available for redistribution 